\title{
On the Philosophical Construction of Discourse Field of Chinese Character
}

\author{
Jianli Tang \\ College of Liberal Arts, Yunnan Normal University, Kunming, China \\ Email: 76070593@qq.com
}

How to cite this paper: Tang, J.L. (2017) On the Philosophical Construction of Discourse Field of Chinese Character. Open Journal of Social Sciences, 5, 260-269. https://doi.org/10.4236/jss.2017.54023

Received: March 14, 2017

Accepted: April 27, 2017

Published: April 30, 2017

Copyright (C) 2017 by author and Scientific Research Publishing Inc. This work is licensed under the Creative Commons Attribution International License (CC BY 4.0).

http://creativecommons.org/licenses/by/4.0/

\begin{abstract}
The generation of Chinese characters, evolution of Chinese characters and the general linkage between the elements of the historical field have constructed the giant discourse field of the Chinese character. The philosophical construction of discourse field of Chinese character provides a new solution for Chinese character research. This paper is based on the Chinese history and reality, beyond the traditional theory of knowledge platform to examine the key value of Chinese characters, revealing the critical points of Chinese characters formation, ideology and value orientation. The relationship between Chinese character formation and thinking, ideology, culture mode, and academic form in a certain historical context is the basis of reconstructing and locating the value of Chinese philosophy.
\end{abstract}

\section{Keywords}

Chinese Character, Discourse Field, Philosophy, Language

\section{Introduction}

The Chinese Characters are not isolated phenomena since its emerging as an historical symbols and cultural medium. All kinds of factors among the inner structure of the Chinese Character, the meanings of the Chinese Characters, the Chinese Characters, the Chinese Characters' birth, the Chinese Characters' development and the historical fields have general linkage. This kind of general linkage has gradually formed a gigantic discourse field. The surface structure of this discourse field is a semantic system, and the inner structure of this discourse field is a hidden cultural system. The philosophy expression plays a core role in this cultural system. It makes philosophical constructing of the Chinese Characters' discourse field possible because of the history and logic of the Chinese Characters' developing. This kind of philosophical constructing objectively has- 
tens the birth of the new research method to study the Chinese Characters. Studying the Chinese Characters should not stay on the intellectualism, but rooting in Chinese history and real life, and form a credit inspecting contrast to traditional culture.

\section{Chinese Characters and the Study of Chinese Characters}

The Chinese Character is a kind of historical existence, but it is not only a tool to record the historical literature, and the process of forming and developing their shapes contains many culture information and ideology which are much earlier or much more than the historical record. In some sense, the Chinese Character has double values of information materials from the diachronic and synchronic perspective. The reality of the information and thinking contained in the Chinese Character even overpasses the historical literature. As we know, the Chinese Character is used to record language and history documents, but this kind of Chinese Character is obviously different from the isolated form-meaning Chinese Character because recording historical literature cannot avoid the affluence of individual and group benefits, or the individual thought about the history and events. So it embodies the discourse hegemony and value standard of individuality and groups, but the isolated Chinese Character is accepted through common practice, it can really reflect that-time cognition through the distinctive formmeaning system.

It has developed the far-reaching and long-history traditional philology to study the Chinese Character. We can say the history of Chinese academy thoughts is the history of commentary and subcommentary to the ancient Chinese books. To check the Chinese Character's meanings in order to grasp the meanings of the ancient Chinese language, or the explanation tradition to disclose the thoughts contained in the ancient Chinese language, the researcher of the traditional philology and the thinker all express themselves in commentary and subcommentary to the ancient Chinese books. Why the academic thoughts consisted of institutions and ideology can be constructed on the commentary and subcommentary to the ancient Chinese books?

Firstly, the Chinese language characteristic of isolated language can focus more attention on subjective explanation made by the readers based on their experiencing.

Secondly, it is much important point that the visional properties and intuitive contained in the Chinese Character's forming and capturing the image of outer world adapts to the perceptual features that Chinese thinking stresses the specific images. It is regrettable that the method of the commentary and subcommentary to the ancient Chinese books is mainstream of the academic thought all time, which is a I-explain-the-classics way focusing on the theme of annotating the ancient books, except for the transient period in the Han Dynasty when the new text school played a big role. Namely, the Five-classics-explain-me paradigm of philosophy thinking is submerged in checking the form, sound and meaning of Chinese Character all the time. 
This kind of academic thought is still on after experiencing the traditional academy summit in the Qian-jia period in the Qing Dynasty. The academic thinking highly valued the checking on the motivation and reasoning continues to contemporary era. It did not come to the expected achievements from the wide and depth though the upsurge of studying language culture and Chinese Character culture sprang up in the 80 s of the 20 century.

In nature, study of Chinese Character culture did not divorce from the old thoughts paradigm of studying the Chinese Character because this study has paid more attentions on the analyzing and checking on the naming and describing the things, the regulations and the customs which base on the original meanings of Chinese Character. And this study ignores the historical logic of Chinese Character's germination and development, the inner and outer relationship, describing the static and dynamic process, the relevancy between Chinese Character's germination and historical field, arranging the germination of Chinese Character's meanings and logic development and the thinking reality of Chinese Character. In short, nowadays studying Chinese Character lacks the philosophical perspective.

Derrida (1999) [1] has put out a core idea in On the Literal Studies which thoroughly subverted logo centrism which occupied a dominant position over 2000 years in the west academic circle. He considered that the concept of writing gradually goes beyond the language through the slow and inevitable movement which lasts over 2000 years. At last, all things Converged in the name of the language turn back to writing once again, or they are concluded in the name of writing. The concept of writing is not used to indicate the special form of an general language, the sub forms and affiliation forms (no matter people consider it as communication, relationship, expression, meanings, idea or the construction of mind, and so on). It no longer indicates the surface of language, no longer indicates a kind of copy of main signifiers, and no longer indicates the signifying the signifier. And Derrida believes that it is a necessary and hard task to establish writing science and writing philosophy. The writing described by Derrida is a kind of original writing, we can say, it is a kind of ideographic writing in which Chinese characters can look as the representative. Based on the special form-meaning structure of Chinese Character, it is of feasibility to establish the writing centrism and necessity to construct the Chinese Character philosophy.

Marx considered that any true philosophy is the essence of the spirit of the times. The philosopher's growth is not like the bamboo shoots after raining. They are the products of their own era and their own people. The finest, the most precious and the essence which cannot see are concentrated in minds of philosophy.

The unique era mark of the generation of Chinese characters embodies the most delicate and precious time spirit and national spirit.

Philosophical reflection of Chinese characters is reflection and construction of the Chinese Character system and internal and external relationship from a philosophical perspective, through all sorts of static structure of Chinese Character 
and dynamic changes of the system Chinese characters. From the perspective of philosophical epistemology and value theory, we explore thinking status, values and way of life, moral standards, customs, aesthetic factors and the inherent development contradictions contained in Chinese characters system.

Chinese character has the philosophy of Chinese characters. Chinese character is the Chinese character of philosophy. This is an extremely valuable cultural heritage of Chinese characters and quality and style of Chinese characters. The philosophical study of Chinese characters is to seek the philosophical orientation of Chinese characters in this system. The main purpose of the study of Chinese characters is to link the development and evolution of Chinese characters with the historical and realistic links, focusing on the internal and external relations of the development of Chinese character system and the concept of the mapping of individual Chinese characters unit.

\section{History of Philosophy Study of Chinese Character}

Introduce to the Chinese character philosophy written by Li Minsheng (2000) [2] has discussed the relationship between Chinese characters and thinking, the development law of Chinese characters, the structure meanings of Chinese characters, the occurrence of Chinese philosophy and other issues. But the research is only an example. The authors of the book focused more on the good points and bad points of the Chinese character.

Guan Zhui Bian written by Qian Zhongshu (1979) [3] pays attention to the philosophy phenomenon of the Chinese characters in the first volume. The opening of the book talked about Hagel mentioning two contrast meanings contained in the same writing based on the German example "Aufheben", "extinction" and "preservation". Mr. Qian cited the case to verify Hagel's dialectical theory.

The Structure and Evolution of Chinese Characters by Liang Donghan (1959) [4] uses Marx Doctrine and Linguistics by Stalin as the theoretical basis, and the research involves the external and internal contradictions in the development of Chinese characters system. He considered that the main contradiction of Chinese charater is the contradiction of Chinese characters writing and speech.

Some parts of the chapter and content of Chinese Character Psychology written by Yao Ganming (2001) [5] use psychology theory to investigate the origin of Chinese characters and the original thinking, the relationship between Chinese characters and philosophy. China Character and Confucianism written by Zang Kehe (1996) [6] explores the relevance between the configuration meanings of Chinese character and Confucianism from the textual research history of Chinese characters units. Philosophy of Writing-Thinking About the General Law of the Writing Study written by Cao Nianming (2006) [7] has discussed the possibility of establishing the common philosophy of general writing and the way to realize the basic principles, including the thinking which takes Chinese characters as an example.

The study of calligraphy aesthetics and Chinese character culture which is re- 
lated to philosophy is quite abundant. The aesthetic study of calligraphy has sprung up after the publication of The Aesthetic Thought of Chinese calligraphy written by Mr. Zong Baihua in 1962 [8]. Explanation of Chinese Characters Calligraphy Aesthetic Category written by Kochi Leeji (2006) [9] and Ten Lectures of Calligraphy and Culture written by Ge Chengyong (2007) [10] explores cultural value and aesthetic value of Chinese characters calligraphy from different perspectives. 1980s cultural upsurge also objectively gave birth to the birth of the Chinese character culture. The study of Chinese characters culture now seems to have a splendid sight, but most of them are farfetched. They have interpreted the meaning of Chinese character without real understanding and have gone beyond the basic path in which people use Chinese character to verify history.

Serious Study on Chinese characters culture is represented by Cultural Studies of Chinese Characters written by He Jiuying (2000) [11], as well as Overview of Chinese Character edited by He Jiuying. Overview of Chinese Character expounds the linkage between Chinese characters and ancient social life in detail, but does not explicitly involve the specific interpretation of the philosophy and culture. The Ancient Chinese characters and Chinese civilization written by $\mathrm{Ge}$ Yinghui (2010) [12] has examined the unearthed literature and historical documents, to explore the historical way of the Chinese character's birth and multiplying, and to trace long history of the origin and development of Chinese civilization. The lack of philosophical reflection is a common problem in the major study of Chinese characters.

Papers on behalf of the research of Chinese characters philosophy are: Substitute and Interval-From the Perspective of Derrida's Philology overview the Philosophical Connotation of Chinese Characters was written by Jiang Yuhui (2006) [13]. Speech Centered and Writing Centered Theory was written by Pan Derong (2002) [14]. Thoughts of China Calligraphy Aesthetics was written by Zong Baihua (1962) [15], and so on. These papers mainly have analyzed the philosophical connotation and value of Chinese characters from the macroscopic angle. Other papers mainly related to the Chinese character and thinking, the dialectical character of Chinese characters and the reform of Chinese characters and other aspects of this issue. This paper will not repeat them because of space.

Besides the above research literature directly related to Philosophy and culture of Chinese characters, there are a number of important works of philosophy research which have an important reference value to study Chinese characters. They mainly include: Essay on Man by Cassirer, Cultural Philosophy by Schweitzer, Ancient society by Morgan, Primitive culture by Taylor, The golden bough by Fraser, Original thinking by Levi Bruhl, Cultural theory by Malinowski. Savage thought by Levi Strauss, etc.

\section{Chinese Character and Relevant Factors}

Chinese character is the symbol system of the concept expression, and the development of this system is dominated by the deep structure which appears as a variety of cultural patterns. The process of the occurrence and development of 
Chinese characters is the generation process of Chinese characters. The formation process of Chinese characters is not only the generation of its own formation which includes the form and structure, but also the generation of the concept formation and value orientation which are closely related to the structural meaning.

The generation of Chinese characters is a dynamic development process in a certain historical field. This paper examines Chinese characters value based on the Chinese history and reality and beyond the traditional theory of knowledge platform. We can say this is an important path to reveal Chinese characters formation, ideology and value orientation. It is the key to reconstruct and locate the value of Chinese philosophy to grasp the relationship between Chinese character generation and thinking, ideology, culture mode and academic form in a certain historical context.

\section{Issues about Philosophy Construction of Chinese Character's Discourse Field}

The study of Chinese characters philosophy aims to rely on the traditional philology based on Marx philosophy as the theoretical basis, using the historical materialism, exploring the historical connection and reality dimension of Chinese characters system and the development of Chinese characters, revealing the inherent contradictions generated in the process of Chinese characters, reflecting the cultural and philosophical significance of Chinese characters revolution and Chinese character's prospect debate. Philosophy construction of Chinese character's discourse field mainly concerns the following issues.

\subsection{Chinese Characters and Thinking Mode}

Chinese characters mold the thinking mode. The occurrence of Chinese characters reflects some of the characteristics of the original thinking. The original thinking has intuitive and concrete characteristics. It can have been reflected from the early carving symbols and hieroglyphs being of very strong picture properties. The thinking of creating Chinese characters has the features of the original thinking that people think from mind images to concepts, usually using a specific image to express an abstract concept. The other characteristic of primitive thinking is the subject consciousness and the object of outer world unify together.

\subsection{Historical Formation of Chinese Characters}

The historical formation of Chinese characters mainly experiences the representative forms from the Oracle, bronze, Xiaozhuan, Lishu to kaishu. The direct motive force of historical evolution of Chinese character formation comes from the social need, the scientific and technological progress, the political reform and the religion, culture and other factors. "Shutongwen" should not be understood as a single official written specification of Qin dynasty. Chinese people use unified Chinese characters from the date of Chinese character's production. Xiao- 
zhuan has only standardized and unified forms system after going through "sound different, writing different" in the Warring States period. If the Confucian expression just meets the functional requirements of unification paradigm of culture, so writing in the same Chinese characters has built a solid foundation for this paradigm. The function of expressing meanings of Chinese characters structure and beyond space of dialect communication of Chinese characters fit the cultural paradigm of unification.

The change from the official script in Han dynasty to Xiaozhuan is called libian. The production of the official script in Han dynasty is a self transcendence of Chinese characters' development. It fundamentally symbolizes the Chinese characters, so it is the start of modern script, and the Chinese characters before the official script in Han dynasty are defined as ancient Chinese characters. The production of the official script in Han dynasty not only has epoch-making significance in the form development of Chinese characters, but also directly results in the different forms of classics. The debate between classical classics (the classics written in Chinese characters in War-states period) and modern-script classics (classics in Chinese characters in the official script in Han dynasty) caused the historical division of Chinese Hermeneutics, namely, classical classics is traditional hermeneutics which explained the classics to avoid misunderstanding, and modern-script classics is philosophical hermeneutics which emphasize the subject interpretation. The original aim of Shuowen Jiezi written by Xu Shen (the Donghan dynasty) [16] is to quell the controversy, so the book has adopted the opinions from these two schools. The interpretation from the school of modern-script classics has a deep philosophical meaning.

\subsection{Generation of Chinese Character}

Language is the direct reality of thought. And thoughts come true the possibility of the existence of Chinese characters. The structure meaning of Chinese characters (original meaning) is closely related to the recorded concept and formation. This kind of idea formation is of the directions of multiple dimensions. The relationship between Chinese characters and life, Chinese characters and power is a good reflection of the real-life dimension of Chinese characters. The meanings of Chinese characters configuration are based on the method "far taken from the objects, nearly taken from the body". They show us the true picture of this world. Through the structure meanings of Chinese characters, we can trace the signs of power generation.

About the power generation, scholars have such different viewpoints as the god awarding, possession of resource, coexistence and differences etc. The Oracle shape and meaning of the Chinese character "Wang" and "father" support the opinion that the power derives from the difference. "King" is a kind of battle-axe weapon, and "father" is like a hand with an axe. Force is an important embodiment of personal ability. Both kingship and patriarchy are derived from this difference. The original form and meaning of Chinese characters have constructed the logical starting point of Chinese philosophy. The structure characte- 
ristic of Chinese characters and the reverse meaning of the Chinese characters have obvious dialectical thinking.

\subsection{Evolution of Chinese Character}

The complex forms of Chinese characters aim to clearly recorded language to comply with the law of distinction. Simplification of Chinese characters is a convenient way to follow the law of simple writing. The law of distinction is restricted by the language development, and the simple law is restricted by the social development. Double restriction of complex and simplification of Chinese characters and antinomy make Chinese characters keep a necessary tension between accurately recording the language and adapt to the social requirements to maintain the system simple. It maintains the stable and balanced development of Chinese characters. Chinese character has been following its own historical logic to movement forward.

The value of Chinese characters has experienced the evolution from divinity to the king, from the king to the nature of the crime. Reform of Chinese characters was over 100 years, which is the reality reflect that the Chinese characters contribute to the national underdevelopment. The new culture movement caused by modern worship and revolutionary fantasy exactly looks Chinese characters revolution as the historical context. The debate on the future of Chinese characters is essentially the ideological conflict caused by the simultaneous appearance of different values. The path of civilization is the presentation of cultural consciousness. The future of Chinese characters is not only to comply with the contradictions of Chinese characters, but also to observe the overall orientation and value of the national culture.

\section{The Significance, Methods and Principles of Philosophy Study of Chinese Characters}

\subsection{Significance of Philosophy Study of Chinese Characters}

The significance of philosophy Study of Chinese characters can describe from three aspects: Firstly, if we consider Chinese characters within the field of the history and reality, it can provide a new path to solve the philosophy study and culture research of Chinese characters, and it can enhance the study breadth and study depth of the Chinese characters.

Secondly, if we can grasp the internal contradiction of the development of Chinese characters and the understanding of the relationship between Chinese characters and real life, it can help to reflect on the reform of Chinese characters and the future debate of Chinese characters, can it can solve the practical difficulties faced by Chinese characters.

Thirdly, philosophical study of Chinese characters reflects a basic theory dimension of how to Chinalize Marx's philosophy, that is, it can help solve China's practical problems with the viewpoint and method of Marx's philosophy. Of course, Chinese characters are in the boundary of the reality of China. The historical materialism of Marx's philosophy provides an important methodological 
guidance for the study of Chinese characters in the historical perspective.

\subsection{Methodological Innovations}

The research method of Chinese character has three methodological innovations in 20th Century. For the first time, Zhang Taiyan published the study of language and characters in 1906, which included the study of Chinese characters into the category of linguistics. This innovation of the Chinese character, phonology, exegesis makes the traditional philology began to bid farewell to the traditional language barriers, and into language category.

The second time is represented by Mr. Tang Lan, with Zhang's contrary, Tang Lan's idea is to separate the language from the linguistics.

The third time is to use the theory of culture study to the study of Chinese characters in the last century in 80s. The philosophy of Chinese characters, broadly speaking, belongs to the category of Chinese character culture. The method and path of philosophy research provides basic methodology guidance for Chinese character research.

\subsection{General Principles}

The general principles of methodology construction of Chinese characters are: the combination of micro and macro research, the combination of local and global research, the combination of internal and external research. As a guide, the specific methods of Chinese character study mainly follow this method.

One is the empirical method, textual research and facts. Two is the method of the unification of history and logic, that is, the method of history and the method of logic are unified. We should reveal the law of the history development of Chinese characters according to the historical development of Chinese characters in the natural process. And we should understand the Chinese character from the theoretical form with presenting the historical process of Chinese characters in a logical way. Follow the method of combining history and logic, we should explore historical connection system and reality of the development of Chinese characters, reveal the inherent contradictions in the generation process of Chinese characters, and reflect cultural and philosophical significance of the reform and future debate of Chinese characters.

\section{References}

[1] Derrida (1999) On the Writing Study. Shanghai Translation Publishing House, Shanghai.

[2] Li, M. (2000) A Preliminary Study on Chinese Character Philosophy. Social Science Literature Press, Beijing.

[3] Qian, Z. (1979) Guan Zhui Bian. Zhonghua Publishing House, Beijing.

[4] Liang, D. (1959) The Structure and Evolution of Chinese Characters. The Publishing House of Shanghai Education, Shanghai.

[5] Yao, G. (2001) Chinese Character Psychology. The Publishing House of Guangxi Education, Nanning. 
[6] Zang, K. (1996) China Character and Confucianism. Academy Study, No. 11.

[7] Cao, N. (2006) Philosophy of Writing-Thinking about the General Law of the Writing Study. Bashu Publishing House, Chengdu.

[8] Zong, B. (2011) Aesthetic and Artistic Conception of Zongbaihua's works. The Commercial Press, Beijing.

[9] Toshiharu, K. (2006) Explanation of Chinese Characters Calligraphy Cesthetic Category. The Publishing House of Shanghai Social Science College, Shanghai.

[10] Ge, C. (2007) Ten Lectures of Calligraphy and Culture. The Relics Publishing House, Beijing.

[11] He, J. (2000) Culture of Chinese Characters. Liaoning People’s Publishing House, Shenyang.

[12] Ge, Y. (2010) Ancient Chinese Characters and Chinese Civilization. Shanghai Publishing House of Ancient Book, Shanghai.

[13] Jiang, Y. (2006) Substitute and Interval-From the Perspective of Derrida's Philology Overview the Philosophical Connotation of Chinese Characters. Monthly Academy Journal, No. 12.

[14] Pan, D. (2002) Speech Centered and Writing Centered Theory. Academic Forum, No. 2.

[15] Zong, B. (1962) The Aesthetics Thoughts in Chinese Calligraphy. Philosophy Study, No. 2.

[16] Xu, S. (2009) Shuo Wen Jie Zi. Zhonghua Book Company, Beijing.

Submit or recommend next manuscript to SCIRP and we will provide best service for you:

Accepting pre-submission inquiries through Email, Facebook, LinkedIn, Twitter, etc. A wide selection of journals (inclusive of 9 subjects, more than 200 journals)

Providing 24-hour high-quality service

User-friendly online submission system

Fair and swift peer-review system

Efficient typesetting and proofreading procedure

Display of the result of downloads and visits, as well as the number of cited articles

Maximum dissemination of your research work

Submit your manuscript at: http://papersubmission.scirp.org/

Or contact jss@scirp.org 